\title{
Avaliação do efeito da clorpromazina sobre a função renal de cães submetidos à isquemia e reperfusão ${ }^{1}$
}

\author{
Liliana B. de Menezes ${ }^{2}$, Maria Clorinda S. Fioravanti ${ }^{3}$, Marcelo S. de Brito e \\ Silva ${ }^{4}$, Leandro G. Franco ${ }^{5}$, Tatyane Penha Sales ${ }^{5}$, Mariana M. Andrascko ${ }^{5}$, \\ Julio César C. Veado 6 e Eugênio G. de Araújo ${ }^{3}$
}

\begin{abstract}
Menezes L.B., Fioravanti M.C.S., Silva M.S.B., Franco L.G., Sales T.P., Andrascko M.M., Veado J.C.C \& Araújo E.G. 2010. [Evaluation of chlorpromazine effect at renal function in dogs submitted to ischemia and reperfusion.] Avaliação do efeito da clorpromazina sobre a função renal de cães submetidos à isquemia e reperfusão. Pesquisa Veterinária Brasileira 30(2):108-114. Setor de Patologia Geral, Instituto de Patologia Tropical e Saúde Pública, Universidade Federal de Goiás, GO 74605-050 Goiânia, Brazil. E-mail: lilianab3@ netscape.net

Renal ischemia may occur in different situations such as vascular or renal surgery and also in renal transplantation. This study evaluates renal function in dogs submitted to ischemia and reperfusion after chlorpromazine application. Twelve adult mongrel dogs were distributed into two groups with six animals each. Group A was composed of dogs submitted to renal ischemia and reperfusion without previous administration of chlorpromazine. Group B was composed of dogs with renal ischemia and reperfusion previously treated with chlorpromazine. In order to evaluate the possible ischemia/ reperfusion late effects, blood and urine samples were sampled in four different times: Before ischemia, early stages of reperfusion, 120 minutes after reperfusion, and every week until 28th day postsurgery. Renal function was evaluated by clinical examination, serum urea and creatinine levels and urinary GGT activity. PU/CU and GGT urinary activity were more sensitive in detecting acute tubular injury than routine urine examination because these variables showed earlier changes. Based on urinalysis, urea and creatinine serum levels plus urinary excretion of GGT and PU/CU, no evidences of protective action of chlorpromazine were observed.
\end{abstract}

INDEX TERMS: Fenotiazinic, gamma-glutamiltransferase, acute renal failure.

RESUMO.- A isquemia renal está presente em diferentes situações como em cirurgias renais, vasculares e no transplante renal. $\mathrm{O}$ objetivo deste trabalho foi avaliar a integridade e a função renal de cães submetidos à isquemia e

\footnotetext{
${ }^{1}$ Recebido em 10 de julho de 2009.

Aceito para publicação em 17 de agosto de 2009.

2 Setor de Patologia Geral, Instituto de Patologia Tropical e Saúde Pública, Universidade Federal de Goiás (UFG), Goiânia, GO 74605050, Brasil. *Autor para correspondência: lilianab3@ netscape.net

${ }^{3}$ Departamento de Medicina Veterinária, Escola de Veterinária, UFG, Goiânia, GO 74605-050.

${ }^{4}$ Hospital Veterinário, Faculdades Objetivo, Goiânia, GO 74605-050.

${ }^{5}$ Graduação em Medicina Veterinária, Escola de Veterinária, UFG, Goiânia, GO.

${ }^{6}$ Departamento de Clínica e Cirurgia Veterinária, Escola de Veterinária, Universidade Federal de Minas Gerais (UFMG), Belo Horizonte, MG 30123-970, Brasil.
}

reperfusão com ou sem aplicação de clorpromazina. Para tanto foram utilizados 12 cães distribuídos aleatoriamente em dois grupos de seis indivíduos: grupo A com isquemia e reperfusão sem tratamento por clorpromazina e o grupo $B$ com isquemia e reperfusão tratados previamente com clorpromazina. De cada cão foi coletado sangue e urina antes da isquemia, no inicio da reperfusão, após 120 minutos de reperfusão e semanalmente até $28^{\circ}$ dia pós-cirúrgico para verificar possíveis efeitos tardios da isquemia/reperfusão. Avaliações da integridade e função renal foram feitas por exame físico, concentração sérica de ureia e creatinina e determinação da GGT urinária. A avaliação da relação proteína urinária/creatinina urinária (PU/CU) e atividade da GGT urinária são exames mais sensíveis para detectar lesão tubular aguda que o exame de urina de rotina, uma vez que estas variáveis 
apresentaram alteração mais precocemente. Não houve ação protetora da clorpromazina conforme constatado por meio da urinálise, dosagens séricas de ureia e creatinina, excreção urinária de GGT e PU/CU.

TERMOS DE INDEXAÇÃO: Fenotiazínico, gama-glutamiltransferase, insuficiência renal.

\section{INTRODUÇÃO}

Isquemia é a perda do suprimento sanguíneo por redução do fluxo arterial de um tecido, em que há comprometimento da oferta de substratos metabólicos, incluindo a glicose (Cotran et al. 2000). Reperfusão é o termo utilizado para definir o restabelecimento do fluxo após um período de isquemia (Evora et al. 1996). A isquemia, por si só, é bastante lesiva, mas a reperfusão do tecido isquêmico pode levar a uma série de complicações, que podem aumentar as lesões teciduais e, associado às complicações sistêmicas, colocar em risco a vida do paciente (Calvert et al. 2003).

O entendimento dos mecanismos envolvidos nos danos da isquemia/reperfusão é essencial para definir estratégias terapêuticas e minimizar suas consequências. A reação ao oxigênio, após a reperfusão, implica em danos teciduais e inicia uma cascata de respostas celulares deletérias precedendo a inflamação, morte celular e por último, insuficiência do órgão (Fondevila et al. 2003).

Um dos modelos de isquemia/reperfusão mais estudados é a oclusão temporária da artéria renal (Araújo et al. 2002). Os danos causados pela hipóxia nas células tubulares representam o primeiro evento em casos de insuficiência renal aguda. Além da perda da polaridade celular, há ainda produção de radicais livres, entrada de cálcio e ativação de genes para proteção ou regeneração celular (Brezis \& Epstein 1993).

Segundo Kerr (2003) e Forterre et al. (2004), os exames primários mais apropriados para o diagnóstico inicial de uma disfunção renal são ureia e creatinina séricas. Porém, ainda afirmaram que a ureia não é um indicador inteiramente especifico de lesão renal, além de aumentar devido a efeitos pré-renais. Já a creatinina é mais específica e pouco influenciada por efeitos pré-renais. Entretanto, essas substâncias geralmente não aumentam até que mais de $60 \%$ dos néfrons estejam sem função, ou seja, trata-se de um marcador específico, mas de baixa sensibilidade.

Não existem enzimas plasmáticas específicas para avaliar a função renal; entretanto a análise de enzimas urinárias, especialmente a -glutamiltransferase (GGT) pode ser útil na identificação de nefrotoxidade aguda. $A$ enzima GGT está presente na borda em escova dos túbulos contornados proximais renais e sua detecção na urina tem sido apontada como um bom método diagnóstico para lesão ou disfunção tubular renal (Rivers et al. 1996). Esta localização única nas células renais pode demonstrar com facilidade os danos causados por uma injúria isquêmica (Santin et al. 2006).
DiBartola (1997) descreveu que a quantificação da proteína na urina é uma avaliação da função glomerular e/ou tubular. Para Forterre et al. (2004) e Price et al. (2005), a detecção de um aumento na excreção de proteínas tem valor diagnóstico ou prognóstico na detecção inicial e confirmação de doença renal, e a quantificação da proteinúria pode ter valor considerável na avaliação da eficácia terapêutica e da progressão da doença.

Considerando-se a oscilação do volume urinário e da concentração de solutos em uma micção, sugere-se que a avaliação seja feita no volume urinário total de 24 horas (Finco 1995). No entanto, os índices proteína urinária/ creatinina urinária $(\mathrm{PU} / \mathrm{CU})$ substituem com vantagens 0 volume urinário total de 24 horas, já que a creatinina é produzida em uma taxa constante e filtrada livremente. Assim, ao aplicar-se o índice, o efeito do volume de urina sobre a concentração de proteína em uma única amostra é anulado (Rego et al. 2001).

Em transplantes, embora a perfusão com solução própria seja possível e parcialmente eficaz, novos estudos são necessários para evitar a perda da função do órgão doado devido a danos isquêmicos. Intervenções farmacológicas nesses processos apresentam grande potencial de melhorar as condições clínicas em cirurgias que envolvam isquemia e reperfusão (Jaeschke 2003). Dentre as opções recentemente estudadas de pré-condicionamento farmacológico, tem-se a proteção conferida pela clorpromazina cuja ação protetora ainda não foi totalmente esclarecida (Netto et al. 2001, Araújo et al. 2002).

De acordo com Chien et al. (1977), sua ação protetora contra a lesão isquêmica só ocorre quando administrada previamente ao momento da parada de aporte sanguíneo ao tecido. $O$ efeito protetor está associado à alteração do metabolismo do cálcio, recuperação de ATP e perda de fosfolipídios.

O objetivo deste trabalho foi avaliar a integridade e a função renal de cães submetidos a isquemia e reperfusão após a aplicação de clorpromazina.

\section{MATERIAL E MÉTODOS}

\section{Animais e delineamento experimental}

Foram utilizados 12 cães adultos, machos, sem raça definida e com peso entre 10 e $25 \mathrm{~kg}$. Esses cães foram obtidos junto ao Centro de Controle de Zoonoses da Prefeitura de Goiânia. O projeto foi aprovado pelo Comitê de Ética em Pesquisa da Universidade Federal de Goiás sob o protocolo oㅜ 006/2008.

Previamente ao estudo experimental, os cães foram avaliados clinicamente para a identificação de enfermidades sistêmicas e renais que pudessem interferir nos resultados. Foi realizada ainda coleta de urina e sangue para hemograma e pesquisa de hemoparasitos para ratificação das condições de higidez orgânica. Durante o período experimental os cães foram mantidos em boxes individuais de alvenaria, tinham acesso livre ao solário, água ad libitum e ração comercial com proteína bruta de $22 \%$ em duas porções diárias. Os cães foram divididos em dois grupos de seis indivíduos: Grupo A, cães submetidos a isquemia e reperfusão sem clorpromazina, e Grupo B, cães medicados com clorpromazina e submetidos a isquemia e reperfusão. 


\section{Cirurgia e pós-operatório}

Os cães foram submetidos à indução anestésica com aplicação de propofol intravenoso ${ }^{7}$ e manutenção anestésica com halotano ${ }^{8}$. A pressão arterial média foi aferida por meio da canulação da artéria femoral e aferição direta em manômetro aneroide de acordo com a técnica proposta por Rezende et al. (2002).

Foi realizada uma incisão paracostal esquerda para identificação e isolamento do rim e da artéria renal esquerdos. Após o isolamento da artéria, os cães de todos os grupos tiveram o vaso clampado com auxílio de uma pinça Satinsky. Os cães do grupo $\mathrm{B}$ receberam clorpromazina ${ }^{9}$ via intravenosa, na dose de $5 \mathrm{mg} / \mathrm{kg}, 15$ minutos antes da clampagem do vaso, que teve duração de uma hora. Após este período, a artéria renal foi desobstruída e ao longo de duas horas foram coletadas seis amostras de parênquima renal esquerdo, com utilização de agulha de biópsia para tecidos moles (modelo Tru-cut) ${ }^{10}$ para posterior avaliação histológica.

Após o procedimento cirúrgico os cães foram mantidos em gaiolas individuais, alimentados com ração duas vezes ao dia e água ad libitum. Foi realizada a administração de cloridrato de tramadol ${ }^{11}$ na dose de $0,1 \mathrm{mg} / \mathrm{kg}$, via subcutânea, duas vezes por dia durante três dias e cefalexina ${ }^{12}$ duas vezes ao dia, via oral, por 10 dias. Todos os cães foram doados ao final do experimento.

\section{Avaliações laboratoriais}

Foram realizadas sete coletas de sangue e urina nos seguintes tempos: cinco minutos antes da isquemia $\left(\mathrm{I}^{0}\right)$, após uma hora de isquemia $\left(I^{1 \mathrm{~h}}\right)$, após duas horas de reperfusão $\left(\mathrm{R}^{2 \mathrm{~h}}\right)$ e prosseguiu aos três dias $\left(R^{3 d}\right)$, sete dias $\left(R^{7 d}\right), 21$ dias $\left(R^{21 d}\right)$ e 28 dias $\left(R^{28 d}\right)$, para verificar possíveis efeitos tardios da isquemia/reperfusão. As amostras de sangue foram obtidas por punção da veia jugular e as amostras de urina foram coletadas por meio de micção espontânea ou sondagem uretral.

Os exames físicos e químicos foram realizados na urina recém coletada e posteriormente centrifugada por cinco minutos, para realização da sedimentoscopia.

Para as provas bioquímicas séricas, $8 \mathrm{~mL}$ de sangue foram coletados em tubos a vácuo ${ }^{13}$ sem anticoagulante. O soro foi obtido a partir da centrifugação do sangue total e submetido a congelamento $\left(-20^{\circ} \mathrm{C}\right)$ até o momento da realização dos exames.

A avaliação da integridade e da função renal foi realizada por meio de exame de urina, da determinação da concentração sérica de ureia e creatinina, do estabelecimento da PU/CU e determinação da atividade da GGT urinária.

A dosagem sérica de ureia foi realizada por método enzimático-colorimétrico, por reação com a urease e a leitura feita utilizando-se um comprimento de onda de $610 \mathrm{~nm}$. A creatinina sérica e urinária foram determinadas por método colorimétrico, por reação com o picrato alcalino, sendo realizada a leitura em um comprimento de onda de $510 \mathrm{~nm}$, sendo que a urina foi diluída em água destilada na proporção de 1:25 como citado por Ferreira (2006). A determinação da concentração de proteína urinária foi feita utilizando-se método colorimétrico, por reação com o vermelho de pirogalol, a uma absorbância de $610 \mathrm{~nm}^{14}$.

A PU/CU foi calculada conforme citado por Finco (1995), dividindo-se os valores da concentração de proteína urinária pelos de creatinina urinária, visando a verificação da lesão tubular renal.

A determinação da atividade da GGT urinária foi realizada logo após a coleta com a utilização de reagente comercial (GGT
Liquiform®). Desta forma, para a determinação da GGT urinária, Deschepper et al. (1989) utilizaram a densidade urinária de 1.025 como fator de correção para o fluxo urinário de uma única amostra coletada de cada cão, por meio da seguinte fórmula:

$$
X=\frac{Y \times 25}{Z}
$$

em que, $X$ é a atividade de GGT urinária calculada, $Y$ é a atividade da GGT urinária da amostra e Z corresponde aos últimos dois dígitos da densidade urinária da amostra. Os valores de referência utilizados estão listados a seguir (Quadro 1).

\section{Quadro 1. Valores de referência de ureia e creatinina} sérica, PU/CU e GGT urinária

\begin{tabular}{ccc}
\hline Parâmetro & Valor de referência & Referência bibliográfica \\
\hline Ureia & $27,80-52,60 \mathrm{mg} / \mathrm{dL}$ & Ferreira $(2006)^{*}$ \\
Creatinina & $0,98-1,36 \mathrm{mg} / \mathrm{dL}$ & Ferreira $(2006)^{\star}$ \\
PU/CU & $<1,0$ & Rego et al. $(2001)$ \\
GGT & $13-92 \mathrm{UI} / \mathrm{L}$ & Santin et al. (2006)
\end{tabular}

${ }^{*}$ Cães sem raça definida alimentados com ração com $22 \%$ de proteína bruta.

\section{Quadro 2. Escore de gravidade da lesão renal observada} no exame de urina de rotina

\begin{tabular}{ccc}
\hline & Urinálise & Escore \\
\hline Proteína & + & 1 ponto para cada + \\
Cilindros & Hialinos + & 1 ponto para cada + \\
& Granulosos finos + & 2 pontos para cada + \\
& Granulosos grossos + & 3 pontos para cada + \\
Células & Pélvica + & 1 ponto para cada + \\
& Descamativa + & 1 pontos para cada + \\
& Renal + & 2 pontos para cada + \\
Leucócitos & $1-5$ & 1 pontos \\
& $6-10$ & 2 pontos \\
& $11-15$ & 3 pontos
\end{tabular}

Para realizar correlações estatísticas, criou-se um índice que traduzia a gravidade da lesão renal observada no exame de urina de rotina. Foram utilizados valores atribuídos a cada componente do exame como está explicitado no Quadro 2. O valor final dado a cada cão foi o somatório de pontos de cada item avaliado. Foram observadas hemácias, mas não foram avaliadas, pois sua presença foi creditada às biópsias realizadas.

Após a realização da estatística descritiva para estabelecimento dos valores de média, desvio-padrão e coeficiente de

\footnotetext{
7 Propovan®, Cristália Produtos Químicos Farmacêuticos Ltda, Rua dos Pariquis 3001, Cremação, Belém, PA.

${ }^{8}$ Halotano, Hoechst do Brasil Química Farmacêutica S/A, Av. das Nações Unidas 18001, Santo Amaro, São Paulo, SP.

${ }^{9}$ Amplictil $($, Aventis Pharma Ltda, Av. Morumbi 6954, São Paulo, SP.

10 Healthcare Hospitalar, Rua Cabuçu 159, Lins, Rio de Janeiro, RJ.

11 Tramal®, Pfizer Saúde Animal, Av. Monteiro Lobato 2270, Guarulhos, SP.

${ }^{12}$ Medley S.A Indústria Farmacêutica, Rua Dr Miguel Couto 58, Centro, Sao Paulo, SP.

${ }^{13}$ Vacutainer ${ }^{\circledR}$, Becton Dickinson Ind. Cirúrgicas Ltda, Rua Alexandre Dumas 1976, Chácara Santo Antonio, São Paulo, SP.

${ }^{14}$ Sensiprot ${ }$, Labtest Diagnóstica S.A., Avenida Paulo Ferreira da Costa 600, Lagoa Santa, MG.
} 
variação $(\mathrm{CV})$, procedeu-se o teste de Lilliefors para a determinação da distribuição e homogeneidade dos dados amostrais.

Foi feita a comparação entre os tratamentos e dentro dos tratamentos. Considerando-se que as variáveis não apresentaram normalidade e homogeneidade de variância simultaneamente, utilizou-se o teste não paramétrico de Kruskal-Wallis $(p<0,05)$ e nas comparações múltiplas pareadas o procedimento de Dunn/Teste bilateral de acordo com Sampaio (1998). Foram utilizados os programas SAEG e XLSTAT 2008.

\section{RESULTADOS E DISCUSSÃO}

Ao exame físico da urina, a cor era predominantemente amarelo-citrino nos cinco minutos antes do início da isquemia $\left(1^{\circ}\right)$ e a partir de 3 dias $\left(\mathrm{R}^{3 \mathrm{~d}}\right)$. As amostras obtidas durante o procedimento cirúrgico eram de cor vermelha, devido às biópsias seriadas que foram realizadas. Essa alteração também foi observada por DiBartola (1997), ao afirmar que muitos pacientes exibem hematúria microscópica durante as primeiras 48 horas após a biópsia. A densidade urinária permaneceu com valores dentro da faixa de normalidade citados pela literatura em todos os momentos avaliados, nos dois grupos experimentais.

$\mathrm{O} \mathrm{pH}$ da urina permaneceu entre 6,5 e 8,0, não tendo sido observado a presença de corpos cetônicos, urobilinogênio ou bilirrubina. A proteína variou de traços, na maioria dos cães, mas foi possível encontrar 3+ em um cão do grupo A com três dias e sete dias, diminuindo em seguida para 2+ nas coletas de 21 dias e 28 dias. Já no grupo $B$ encontraram-se traços de proteínas e em três cães foram observadas $2+$ em no máximo dois momentos da coleta. Esses achados indicam proteinúria significante sugerindo lesão tubular, pois segundo Kerr (2003), a urina normal ocasionalmente apresenta traços ou no máximo 1+ de proteína.

Foram encontradas em grande parte dos cães em ambos os grupos cilindros granulosos finos e grossos principalmente no terceiro dia, estendendo até a última coleta $\left(R^{28 d}\right)$. Para DiBartola (1997), os cilindros grosseiramente granulares e finamente granulares representam a degeneração de células em outros cilindros ou a precipitação de proteínas plasmáticas filtradas, sendo sugestivos de lesão tubular renal isquêmica ou nefrotóxica. Neste estudo, a presença dos cilindros foi resultado da morte celular devido à isquemia renal.

A presença de células descamativas do trato urinário inferior foi constante na maioria dos momentos nos cães dos dois grupos. As células renais e pélvicas também foram observadas nos dois grupos, principalmente a partir do terceiro dia. De acordo com DiBartola (1997), as células descamativas do trato urinário inferior podem ser encontradas no sedimento urinário, mas possuem pouco significado diagnóstico, sendo comuns em amostras coletadas por jatos de urina ou por cateterismo. Já as células renais são pequenas células epiteliais oriundas dos túbulos renais, e sua origem renal pode ser determinada quando é observada em cilindros celulares, como no presente trabalho (Fig.1).

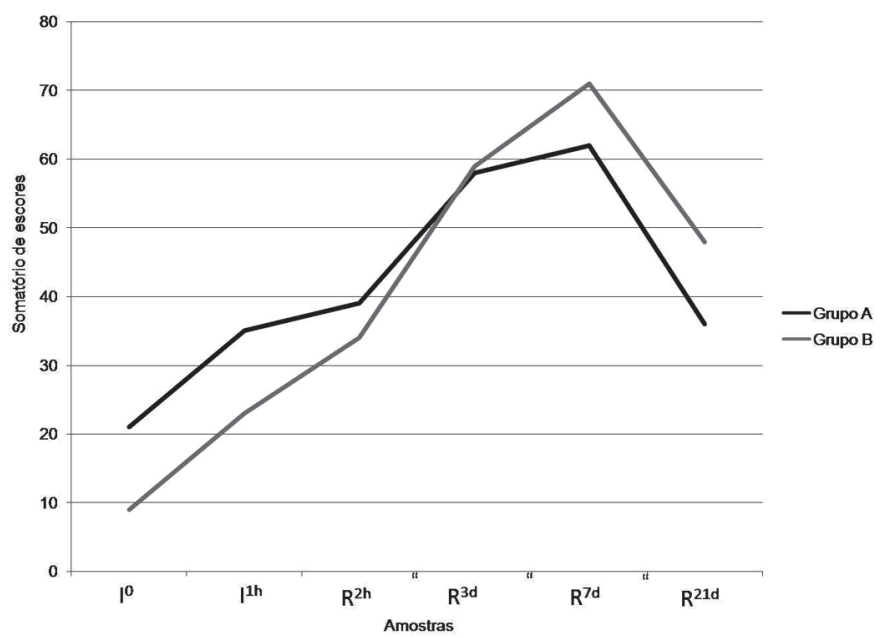

Fig.1. Escores de gravidade da lesão renal diagnosticada no exame de urina de rotina.

A média da creatinina sérica permaneceu dentro dos padrões da normalidade, em ambos os grupos ao longo de todo período (Quadro 3); isto pode ser justificado devido a atividade compensatória do rim direito, que não foi lesionado, uma vez que, conforme Hennemann et al. (1997), uma das características dos rins é sua capacidade compensatória ao prejuízo. Observam-se danos funcionais somente quando houver perda de $3 / 4$ da capacidade funcional dos néfrons de ambos os rins. Foi evidenciado que não houve diminuição da taxa de filtração glomerular uma vez que os valores de creatinina permaneceram dentro da normalidade.

Quadro 3. Índices séricos de creatinina de cães submetidos à isquemia e reperfusão renal, tratados (Grupo $A$ ) ou não tratados (Grupo B) com clorpromazina, ao longo de

28 dias de avaliação, representados pelos valores de média, desvio-padrão e coeficiente de variação (CV), Goiânia, 2008

\begin{tabular}{|c|c|c|c|c|c|c|c|c|}
\hline \multirow{2}{*}{\multicolumn{2}{|c|}{ Grupos }} & \multicolumn{7}{|c|}{ Creatinina sérica } \\
\hline & & $1^{0}$ & $\mathrm{I}^{1 \mathrm{~h}}$ & $\mathrm{R}^{2 \mathrm{~h}}$ & $R^{3 d}$ & $R^{7 d}$ & $R^{21 d}$ & $R^{28 d}$ \\
\hline \multirow[t]{4}{*}{$A$} & Mediana & 0,80 & 0,85 & 0,90 & 1,20 & 1,00 & 1,05 & 0,95 \\
\hline & Média & 0,82 & 0,90 & 0,94 & 1,17 & 1,08 & 1,10 & 1,02 \\
\hline & DP & 0,08 & 0,21 & 0,23 & 0,29 & 0,29 & 0,33 & 0,53 \\
\hline & $\mathrm{CV}(\%)$ & 9 & 21 & 22 & 22 & 24 & 28 & 47 \\
\hline \multirow[t]{4}{*}{ B } & Mediana & 1,00 & 1,00 & 1,20 & 1,25 & 1,25 & 1,15 & 1,15 \\
\hline & Média & 1,04 & 1,10 & 1,18 & 1,25 & 1,27 & 1,23 & 1,17 \\
\hline & DF & 0,21 & 0,25 & 0,26 & 0,24 & 0,33 & 0,30 & 0,27 \\
\hline & $C V(\%)$ & 18 & 20 & 20 & 18 & 24 & 22 & 21 \\
\hline
\end{tabular}

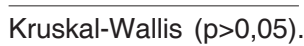

As concentrações séricas de ureia não tiveram diferença estatística entre os grupos ( $p>0,05)$; porém, os valores médios a partir de três dias no grupo $\mathrm{A}$ e sete dias no grupo $B$ permaneceram acima dos valores normais. Este fato pode ser atribuído às alterações metabólicas decorrentes da alimentação (Quadro 4).

São vários os fatores que podem afetar a concentração sérica da ureia o que leva à necessidade de se fazer uma investigação de doença renal junto com os níveis 


\begin{tabular}{|c|c|c|c|c|c|c|c|c|}
\hline \multirow{2}{*}{\multicolumn{2}{|c|}{ Grupos }} & \multicolumn{7}{|c|}{ Uréia } \\
\hline & & $1^{0}$ & $I^{1 \mathrm{~h}}$ & $\mathrm{R}^{2 \mathrm{~h}}$ & $\mathrm{R}^{3 \mathrm{~d}}$ & $\mathrm{R}^{7 \mathrm{~d}}$ & $\mathrm{R}^{21 \mathrm{~d}}$ & $R^{28 d}$ \\
\hline \multirow[t]{4}{*}{ A } & Mediana & 46,70 & 41,55 & 46,50 & 62,70 & 67,40 & 53,60 & 61,75 \\
\hline & Média & 46,18 & 42,90 & 49,10 & 68,02 & 72,15 & 58,22 & 59,32 \\
\hline & DP & 7,96 & 9,54 & 14,87 & 18,09 & 26,74 & 11,05 & 12,00 \\
\hline & CV(\%) & 15 & 20 & 27 & 24 & 34 & 17 & 18 \\
\hline \multirow[t]{4}{*}{$B$} & Mediana & 45,40 & 46,55 & 52,20 & 42,35 & 55,30 & 56,45 & 61,95 \\
\hline & Média & 44,94 & 46,52 & 52,64 & 43,35 & 54,18 & 56,32 & 61,08 \\
\hline & DP & 24,21 & 16,00 & 21,02 & 17,60 & 15,91 & 16,21 & 10,23 \\
\hline & CV(\%) & 48 & 31 & 36 & 37 & 27 & 26 & 15 \\
\hline
\end{tabular}

Kruskal-Wallis $(p>0,05)$.

séricos de creatinina na tentativa de obter o máximo de informações sobre a função dos rins. Entretanto, foi possível verificar que a lesão de isquemia e reperfusão em um rim não foi capaz de induzir a insuficiência renal nestes cães. Conforme Kerr (2003), o hábito de mensurar ureia e creatinina juntas permite que o aumento da concentração de ureia pré-renal seja diferenciado dos quadros renais e efeitos metabólicos e circulatórios podendo ser reconhecidos sem ambiguidade.

A PU/CU urinária foi utilizada para verificar a proteinúria nos cães, substituindo a necessidade de obter amostras do volume urinário total de 24 horas, conforme indicado por Martins et al. (2003) e Ferreira (2006).

A PU/CU não apresentou diferença significativa $(p>0,05)$ entre os grupos, mas foi verificada diferença significativa $(p<0,05)$ entre o terceiro e o sexto momentos em ambos os grupos (Quadro 5). Estes achados podem estar relacionados com agravamento da lesão renal durante o período de reperfusão, uma vez que o aumento nesta relação é geralmente causado por redução na taxa de filtração glomerular e/ou por diminuição da capacidade de reabsorção tubular (Yalçin \& Çetin 2004). Conforme Lima (2004), a necrose tubular aguda é a lesão mais

Quadro 5. Valores da relação proteína/creatinina urinária de cães submetidos à isquemia e reperfusão renal, tratados (Grupo A) ou não tratados (Grupo B) com clorpromazina, ao longo de 28 dias de avaliação, representados pelos valores de média, desvio-padrão e coeficiente de variação (CV), Goiânia, 2008

\begin{tabular}{|c|c|c|c|c|c|c|c|c|}
\hline \multirow{2}{*}{\multicolumn{2}{|c|}{ Grupos }} & \multicolumn{7}{|c|}{ Proteína/creatinina urinária } \\
\hline & & $1^{0}$ & $I^{1 \mathrm{~h}}$ & $\mathrm{R}^{2 \mathrm{~h}}$ & $R^{3 d}$ & $\mathrm{R}^{7 \mathrm{~d}}$ & $R^{21 d}$ & $R^{28 d}$ \\
\hline \multirow[t]{4}{*}{ A } & Mediana & 0,70 & 2,52 & $4,20^{a}$ & 0,65 & $0,30^{b}$ & $0,30^{b}$ & 0,40 \\
\hline & Média & 0,63 & 2,90 & 4,55 & 1,20 & 0,65 & 0,38 & 0,75 \\
\hline & DP & 0,24 & 2,35 & 2,07 & 1,14 & 0,90 & 0,22 & 0,97 \\
\hline & $\mathrm{CV}(\%)$ & 34 & 72 & 41 & 87 & 127 & 52 & 118 \\
\hline \multirow[t]{4}{*}{ B } & Mediana & 0,31 & 0,52 & $2,53^{a}$ & 0,50 & 0,26 & $0,19^{b}$ & 0,18 \\
\hline & Média & 0,41 & 1,03 & 3,34 & 0,74 & 0,83 & 0,60 & 0,80 \\
\hline & $\mathrm{D}$ & 0,26 & 1,37 & 2,63 & 0,74 & 1,34 & 1.06 & 1,01 \\
\hline & $\mathrm{CV}(\%)$ & 58 & 122 & 72 & 92 & 145 & 162 & 113 \\
\hline
\end{tabular}

abMédias seguidas por letras diferentes, dentro da mesma linha, diferem estatisticamente pelo teste de Kruskal-Wallis $(p<0,05)$. comum em casos de isquemia e reperfusão renal, e que pode ter levado à diminuição da reabsorção tubular de proteínas, aumentando a $\mathrm{PU} / \mathrm{CU}$. A isquemia provocou um ligeiro aumento na $P U / C U$ e a reperfusão provocou aumento significativo quando comparado $\mathrm{I}^{\text {th }}$ e $\mathrm{R}^{2 \mathrm{~h}}$ nos grupos A e B.

Ocorreu um aumento das médias da atividade da GGT urinária, porém com elevada variação entre os indivíduos, este fato foi observado por Santin et al. (2006) ao realizarem acompanhamento laboratorial da função renal de cães sadios tratados com anfotericina B.

A isquemia não ocasionou aumento da atividade da GGT, somente a reperfusão, não sendo possível evidenciar diferença estatística $(p>0,05)$ entre os dois grupos. Este resultado pode indicar um agravamento da lesão renal após o período de reperfusão, uma vez que, segundo Evora et al. (1996), a isquemia tem papel fundamental em muitas situações clínicas. Apesar da reperfusão de um órgão isquêmico ser essencial para prevenir a irreversibilidade da lesão celular, a reperfusão pode agravar as lesões produzidas na fase isquêmica isolada, conforme constatado no presente trabalho.

A diferença estatística dos valores de GGT urinária entre os momentos foi observada somente no grupo $B$, após $2 \mathrm{~h}$ de reperfusão $(115,62 \pm 55,20)$ e 28 dias após o procedimento $(27,52 \pm 14,50)$, evidenciando a diminuição para os parâmetros normais de excreção da GGT (Quadro 6). Araújo et al. (2002) utilizando ratos, observaram alteração na função renal do grupo submetido à isquemia e previamente tratado com clorpromazina, na dosagem de $3 \mathrm{mg} / \mathrm{kg}$ via IV, que não foi estatisticamente significativo.

Observou-se que os valores da atividade de GGT, cinco minutos antes do procedimento nos dois grupos, foram mais altos que os encontrados na última amostra, apesar de permanecerem dentro dos limites normais considerados. Isto deveu-se possivelmente à hipotensão que ocorreu como consequência do procedimento anestésico e pela própria aplicação da clorpromazina, determinando

Quadro 6. Índices excreção urinária de GGT de cães submetidos à isquemia e reperfusão renal, tratados (Grupo A) ou não tratados (Grupo B) com clorpromazina, ao longo de 28 dias de avaliação, representados pelos valores de média, desvio-padrão e coeficiente de variação (CV), Goiânia, 2008

\begin{tabular}{|c|c|c|c|c|c|c|c|c|}
\hline \multirow{2}{*}{\multicolumn{2}{|c|}{ Grupos }} & \multicolumn{7}{|c|}{ GGT urinária } \\
\hline & & $1^{0}$ & $\mathrm{I}^{1 \mathrm{~h}}$ & $\mathrm{R}^{2 \mathrm{~h}}$ & $\mathrm{R}^{3 \mathrm{~d}}$ & $\mathrm{R}^{7 \mathrm{~d}}$ & $R^{21 d}$ & $R^{28 d}$ \\
\hline \multirow[t]{4}{*}{$A$} & Mediana & 74,00 & 50,90 & 69,90 & 50,45 & 7,70 & 34,95 & 8,10 \\
\hline & Média & 77,08 & 64,76 & 83,86 & 61,33 & 56,13 & 43,20 & 38,12 \\
\hline & DP & 37,80 & 40,18 & 63,42 & 32,93 & 19,48 & 36,34 & 22,41 \\
\hline & $\mathrm{CV}(\%)$ & 44 & 55 & 68 & 49 & 32 & 77 & 54 \\
\hline \multirow[t]{4}{*}{ B } & Mediana & 38,10 & 73,10 & $95,40^{\mathrm{a}}$ & 38,10 & 31,75 & 28,60 & $22,20^{\mathrm{b}}$ \\
\hline & Média & 86,18 & 86,78 & 115,62 & 57,10 & 30,63 & 31,77 & 27,52 \\
\hline & ת & 70,40 & 41,50 & 55,20 & 41,5 & 12,30 & 12,20 & 14,50 \\
\hline & CV(\%) & 82 & 48 & 48 & 73 & 40 & 38 & 53 \\
\hline
\end{tabular}

ab Médias seguidas por letras diferentes, dentro da mesma linha, diferem estatisticamente pelo teste de Kruskal-Wallis $(p<0,05)$. 
menor fluxo sanguíneo que levou à menor liberação de GGT urinária nestes cães.

Os dois grupos comportaram-se de maneira semelhante ao elevar os valores da atividade de GGT urinária após $1 \mathrm{~h}$ de isquemia e $2 \mathrm{~h}$ de reperfusão. Ward (1975), utilizando cães como modelo experimental, observou que a GGT urinária apresentava aumento significativo após cinco minutos de isquemia renal unilateral e um aumento ainda maior após $90 \mathrm{~min}$; o autor afirmou ainda que a GGT urinária foi utilizada para avaliar a injúria isquêmica associada a transplante renal em seres humanos, obtendo uma boa correlação entre o aumento da atividade enzimática e o diagnóstico clínico de rejeição a transplante.

O aumento da excreção de GGT urinária fornece o diagnóstico da lesão da membrana da borda em escova com perda da estrutura da microvilosidade e, de acordo com Vianna (2006), a lesão dessa estrutura causa diminuição da reabsorção e aumento da excreção de proteínas.

No presente experimento, o aumento da atividade da GGT urinária evidenciou a lesão em células tubulares causada pelo processo de isquemia e reperfusão.

A atividade da GGT urinária e a PU/CU tiveram o mesmo comportamento. No fim do período trans-operatório de reperfusão $\left(R^{2 h}\right)$ houve aumento dos valores nos dois grupos seguindo para a resolução do quadro, em que a recuperação mostrou-se similar. Observando estas variáveis ficou evidente que a função renal retornou à normalidade, e pode ser explicado porque a resposta à lesão isquêmica pode ser dividida em períodos reversíveis ou irreversíveis, sendo que a reversibilidade segundo Chien et al. (1977) está relacionada com a integridade morfológica das células após a reperfusão, a capacidade de recuperar ATP e de regular a concentração de cálcio intracelular. Assim, o registro da atividade da GGT urinária e a PU/CU constituíram-se em um eficiente indicador da recuperação da função renal após o episódio de isquemia e reperfusão e, portanto, estes testes podem ser aplicados para o prognóstico de situações clínicas similares, como por exemplo, transplantes renais.

A dose escolhida de clorpromazina foi de $5 \mathrm{mg} / \mathrm{kg}$, sendo esta acima da dose terapêutica recomendada (1-3mg/ $\mathrm{kg}$ ), e o tempo de isquemia foi de uma hora uma vez que outros trabalhos citam alterações renais após este tempo. Na pesquisa realizada por Netto et al. (2001) não foi possível verificar a proteção conferida pela clorpromazina, tendo os autores atribuído este fato à baixa dosagem da medicação $(2 \mathrm{mg} / \mathrm{kg})$ e ao elevado período de isquemia fria (48 h). Porém, deve-se exercer cautela na escolha da dose de clorpromazina, uma vez que esta quando administrada em altas dosagens pode causar hipotensão grave.

O efeito dos fenotiazínicos na estrutura e função das membranas como bloqueador dos canais de cálcio já é conhecido em outros órgãos, entretanto não foi possível verificar o efeito protetor da clorpromazina mesmo aumentando o tempo de reperfusão e diminuindo o tempo de isquemia como foi sugerido por Netto et al. (2001).
Trabalhos realizados em coelhos sugerem a eficácia da clorpromazina como agente protetor de lesão renal mesmo utilizando uma dose menor que $5 \mathrm{mg} / \mathrm{kg}$ (Dahlanger \& Bilde 1979), outros autores observaram o efeito protetor após isquemia e reperfusão hepática, sendo que foram utilizadas doses maiores $(20 \mathrm{mg} / \mathrm{kg})$ em ratos e com um maior tempo de isquemia (três horas) (Chien et al. 1977). Com isso é possível ressaltar que além da dose utilizada e da duração da isquemia/reperfusão, também deve ser levado em consideração o modelo experimental empregado, além dos métodos de avaliação da função renal, que podem não ser sensíveis para avaliar o efeito protetor conferido pela medicação e simplesmente evidenciar a lesão causada pelo processo de isquemia e reperfusão, como foi encontrado no presente trabalho.

\section{CONCLUSÕES}

Não foi evidenciada ação protetora da clorpromazina na isquemia renal e reperfusão renal nas condições do presente experimento.

A avaliação da PU/CU e atividade da GGT urinária são provas mais sensíveis para detectar lesão tubular aguda que o exame de urina de rotina, uma vez que estas variáveis apresentaram alteração mais precocemente quando comparados aos resultados da ureia e creatinina séricas.

\section{REFERÊNCIAS}

Araújo W.M., Júnior S.T., Costa R.S., Ferreira R.A., Pozza M.L., Mazzeto S.A., Alves P., Cologna A.J. \& Martins A.C.P. 2002. Animal model of ischemic injury, and chlorpromazina protector effect, evaluate by TC99M-MAG3 dynamic renal scan. Acta Cirúr. Bras. 17(3):15-19.

Brezis M. \& Epstein F.H. 1993. Cellular mechanisms of acute ischemic injury in the kidney. Annu. Rev. Med. 44:27-37.

Calvert J.W., Zhou C., Nanda A. \& Zhang J.H. 2003. Effect of hyperbaric oxygen on apoptosis in neonatal hypoxia-ischemia rat model. J. Appl. Physiol. 95(5):2072-80.

Chien K.R., Abrams J., Pfau R.G. \& Farber J.L. 1977. Prevention by chlorpromazine of ischemic liver cell death. Am. J. Pathol. 88(3):539553.

Cotran R.S., Kumar V. \& Collins T. 2000. Robins: Patologia estrutural e funcional. Editora Guanabara, Rio de Janeiro, p.1-26.

Dahlanger J.I. \& Bilde T. 1979. Renografic evaluation of kidney preservation with chlorpromazine. J. Nuclear Med. 20:18-25.

Deschepper J., De Cock I. \& Capiau E. 1989. Urinary gamma glutamil transferase and the degree of renal dysfunction in 75 bitches with pyometra. Res. Vet. Sci. 46:396-400.

DiBartola S.P. 1997. Abordagem clínica e avaliação laboratorial da afecção renal, p.2355-73. In: Etiinger S.J. \& Feldman E.C. (Eds), Tratado de Medicina Interna Veterinária. Editora Manole, São Paulo.

Evora P.R.B., Pearson P.J., Seccombe J.F. \& Schaff H.V. 1996. Atualização: Lesão de isquemia e reperfusão. Aspectos fisiopatológicos e a importância da função endotelial. Arqs Bras. Cardiol. 4(66):239-245.

Ferreira R.P. 2006. Função renal de cães adultos sadios alimentados com diferentes teores de proteína bruta. Dissertação de Mestrado em Ciência Animal, Universidade Federal de Goiás, Goiânia. 105p.

Finco D.R. 1995. Urinary protein loss, p.211-215. In: Osborne C.A. \& Finco D.C. (Eds), Canine and Feline Nephrology and Urology. Editora Williams and Wilkins, Philadelphia. 
Fondevila C., Busuttil R.W. \& Kupiec-Weglinski J.W. 2003. Hepatic ischemia/reperfusion injury-a fresh look. Exp. Molecul. Pathol. 74(2):86-93.

Forterre S., Raila J. \& Schweigert F.J. 2004. Protein profiling of urine from dogs with renal disease using ProteinChip analysis. J. Vet. Diagn. Invest. 16:271-277.

Hennemann C.R.A., Silva C.F., Schoenau W., Kommers G.D., Polydoro A.S. \& Leitzke M.R.M. 1997. Atividade da gamma glutamil transpeptidase urinária, dosagens séricas de uréia e creatinina como meios diagnósticos auxiliares na nefrotoxicidade induzida por aminoglicosídeo em cães. Ciência Rural 27(2):237-244.

Jaeschke H. 2003. Molecular mechanisms of hepatic ischemiareperfusion injury and preconditioning. Am. J. Physiol. Gastrointest. Liver Physiol. 284(1):15-26.

Kerr M.G. 2003. Exames Laboratoriais em Medicina Veterinária: bioquímica clínica e hematologia. Editora Roca, São Paulo, p.87-128.

Lima L.V.S. 2004. Associação da ciclosporina ao precondicionamento isquêmico em rim de rato submetido à isquemia normotermica e reperfusão. Tese de Doutorado em Medicina, Universidade de São Paulo, Ribeirão Preto. 70p.

Martins M.R., Daleck C.R., Carvalho M.B., Calado E.B., Ziliotto L. \& Francisco M.M.S. 2003. Avaliação da função renal de cães sob dois protocolos para administração da cisplatina. Acta Cirúr. Bras. 18(4):314-319.

Netto J.M.B., Tucci Jr S., Colongna A.J., Suad H.J., Martins A.C.P., Molina C.A.F. \& Roselino J.E.S. 2001. Chlorpromazine and mitochondrial function in kidney ischemia-reperfusion. Acta Cirúr. Bras. 16(1):s.p.

Price C.P., Newall R.G. \& Boyd J.C. 2005. Use of protein:creatinine ratio measurements on random urine samples for prediction of significant proteinuria: A systematic. Clin. Chemistry 51(9):1-11.
Rego A.B.A.S., Kogika M.M., Santoro M.L., Hagiwara M.K. \& Mirandola R.M.S. 2001. Eletroforese das proteínas urinárias de cães normais e cães com doença renal em gel de sódio-dodecil-sulfato poliacrilamida (SDS-PAGE). Vet. Notícias 7(2):65-72.

Rezende M.L., Nunes N., Souza A.P. \& Santos P.S.P. 2002. Monitoramento hemodinâmico invasivo em pequenos animais invasive hemodynamic monitoring in small animals. Semina: Ciências Agrárias 23(1):93-100.

Rivers B.J., Walter P.A., O’Brien T.D., King V.L. \& Polzin D.J. 1996. Evaluation of urine gamma-glutamyl transpeptidade-to-creatinine ratio as a diagnostic tool in an experimental model of aminoglycosideinduced acute renal failure in the dog. J. Am. Anim. Hospital Assoc. 32:323-336.

Sampaio I.B.M. 1998. Estatística aplicada à experimentação animal. Editora FEPMV, Belo Horizonte, p.201-221.

Santin F., Moutinho F.Q., Amaral A.S. \& Takahira R.K. 2006. Acompanhamento laboratorial da função renal de cães sadios tratados experimentalmente com doses terapêuticas de anfotericina B. Ciência Rural 36(6):1816-1823.

Vianna P.T.G. 2006. Marcadores biomoleculares da insuficência renal, p.57-61. In: Cavalcante I.L., Cantinho F.A.F. \& Assad A. (Eds), Medicina Perioperatória. Socciedade de Anestesiologia do estado do Rio de Janeiro, Rio de Janeiro.

Ward J.P. 1975. Urinary gamma-glutamyl transpeptidase, an indicator of renal ischaemia injury and homograft rejeiction. J. Urology 47(7):76570.

Yalçin A. \& Çetin M. 2004. Electrophoretic separation of urine proteins of healthy dogs and dogs with nephropathy and detection of some urine proteins of dogs using immunoblotting. Revue de Médecine Vétérinaire 155(2):104-112. 